УДК 334.7

DOI 10.18101/2304-4446-2019-2-24-30

\title{
МОДЕРНИЗАЦИЯ БИЗНЕСА КОМПАНИИ ПОД ВЛИЯНИЕМ ЦИФРОВЫХ ТЕХНОЛОГИЙ
}

\author{
(C) Куликова Елена Ивановна \\ кандидат экономических наук, доцент, \\ Финансовый университет при Правительстве РФ \\ Россия, 125993, г. Москва, Ленинградский проспект, 49 \\ E-mail: kulikovae@yandex.ru
}

Статья затрагивает актуальную тему внедрения в экономическую практику цифровых технологий, поскольку в мировой экономике предъявляются особые требования к их развитию, которое положило начало эре цифровой экономики. В их основе заложены потребности общества в комплексе институциональных реформ, направленных на модернизацию распределительных и перераспределительных отношений. Основное внимание уделено исследованию трансформации бизнес-процессов и бизнес-моделей в результате развития цифровых технологий в различных сегментах функционирования бизнеса - управлении, организации производственных процессов, продажах и др. Автор определяет возможности развития российских компаний и направления использования тех или иных продуктов в бизнес-процессах, а также обрисовывает в общих чертах риски их применения.

Ключевые слова: бизнес-процессы; бизнес-модели; цифровые технологии; онлайнплатформы; искусственный интеллект; предпринимательская деятельность; шеринг экономика.

\section{Для цитирования:}

Куликова Е. И. Модернизация бизнеса компании под влиянием цифровых технологий // Вестник Бурятского государственного университета. Экономика и менеджмент. 2019. № 2. С. 24-30.

В современном мире все более очевидным становится проникновение новых цифровых технологий во все сферы деятельности человека [3; 4]. Возникают новые продукты, услуги, способы коммуникаций, оказывающие влияние и на потребление, и на производство, и на информационное обеспечение в любых отраслях деятельности компаний и человека. Компании стремятся модифицировать бизнес-модели, поскольку преобразование бизнеса с помощью цифровых технологий обеспечивает повышение эффективности и сокращение затрат.

Основной проблемой для компаний в рыночной экономике является создание конкурентоспособного бизнеса, что может быть обеспечено путем решения следующих задач:

- адаптация к современным условиям ведения бизнеса, которая в цифровой экономике достигается путем оцифровки бизнес-процессов; обеспечения вариативности предлагаемых продуктов и услуг в зависимости от потребностей и особенностей клиентов; высокого уровня сервиса; возможности решать вопрос о покупке товара (консультации, получение кредита, заказ и оплата, активация услуги, подтверждение скидок и т. п.) с помощью мобильных устройств - телефона, планшета и проч.; 
- оптимизация бизнеса, что в цифровой экономике означает повышение скорости принятия решений; снижение количества вовлеченных в процесс сотрудников; создание систем самообслуживания, минимизирующих количество медиаторов между клиентом и конечным сервисом или продуктом ${ }^{1}$;

- клиентоориентированность, обеспечивающая предоставление клиенту удобного интерфейса; индивидуального подхода к обслуживанию и продукту; онлайн-чата для просмотра отзывов о продукте и принятия решения о его покупке; высокой скорости и качества оказания услуги.

Подобные задачи возможно решить только путем модернизации бизнеса в направлении либо освоения и внедрения цифровых технологий, либо трансформации бизнес-моделей, требующей изменения под влиянием цифровых технологий механизмов управления, производства, продаж, получения доходов.

В настоящее время на основе цифровых технологий появляются и очень быстро распространяются в экономическом пространстве совершенно инновационные продукты, которых не было на рынке еще 5-10 лет назад, среди них:

- защищенные системы хранения данных на основе технологии блокчейн;

- криптовалюты;

- онлайн-платформы для сбора средств на проекты, в том числе социальные;

- поисковые системы и сервисы (Yahoo, Netscape);

- устройства «умного дома»;

- создание пространственных копий, запчастей на основе 3D-печати;

- смарт-часы, смарт-контракты (могут использоваться для выборов, кредитования, аренды жилья - в случае неуплаты вовремя, доступ прекращается автоматически и т. п.);

- механизмы удаленной идентификации (на основе Big Data);

- Airbnb - аренда отпускного жилья;

- дроны и другой беспилотный транспорт;

- партиципаторное бюджетирование и др. [2, с. 68].

Отличительной характеристикой подобного рода продуктов является то, что зачастую в их основе лежат массивы данных, которые были накоплены компаниями за многие годы и только сейчас в связи с развитием новых технологий для них находится эффективное применение, позволяющее компаниям решать качественно иные задачи. Перечисленные продукты могут быть созданы компанией и применяться в качестве обеспечения производственного процесса в той или иной области деятельности. Таким образом, можно сказать, что цифровые технологии и продукты на их основе позволяют решать качественно иные задачи, т. к. под их влиянием появляются новые экономические механизмы:

- управления (основная характеристика - децентрализация);

- взаимодействия (снижение роли посредников);

- расчетов (эмиссия и использование криптовалют как средства платежей);

- взаимоотношений на рынке труда («франшиза одного лица»²).

\footnotetext{
${ }^{1}$ Фокин М. 6 факторов успеха цифровой трансформации бизнеса [Электронный ресурс]. URL: https://ngmsys.com/blog/business-process-digitalization

${ }^{2}$ Tim O'Reilly. Evolution of the Digital Economy (BGG Henderson Institute and the Institute for New Economic Thinking, September 2018).
} 
В последнее время наблюдается тенденция создания механизмов децентрализации и снижения роли посредников. Эти процессы прослеживаются при анализе бизнес-моделей, функционирующих на основе различных электронных платформ, которые используют такие компании, как Uber; Airbnb, eBay и др. Основной принцип действия подобных компаний состоит в обеспечении доступа пользования, а не владения каким-либо продуктом, ресурсом, благом. Если у кого-то есть ресурс или его избыток, нужный другим, то задача компании - соединить эти возможности и потребности. Такими ресурсами могут быть инструменты, оборудование, автомобиль, жилье, навыки и умения, информация, свободное время.

Общее название данного явления - sharing economy ${ }^{1}$. Основной идеей шеринг экономики является не продажа компаниями продуктов, а предоставление сервисов по использованию продуктов, данной компании не принадлежащих, но отдаваемых во временное пользование тем, кому это необходимо. Наиболее яркими представителями, предоставляющими подобного рода сервисы, как было отмечено ранее, являются компании Uber, не имеющая своего парка автомобилей и постоянного состава водителей; Airbnb, не имеющая своих отелей и апартаментов для сдачи жилья в наем, а предоставляющая сервис, позволяющий тем, кому необходимо жилье в любой точке мира, найти тех, кто готов это жилье сдавать; платформа еВау - американская компания, предоставляющая услуги в областях интернет-аукционов и интернет-магазинов, где осуществляется продажа товаров от официальных продавцов и частных лиц; в нашей стране большую популярность получил сервис BlaBlaCar (международный проект), который позволяет искать попутчиков для поездок на дальние расстояния. Система онлайнрейтинга, отзывов, модерация профилей позволяют вызвать доверие между незнакомыми людьми, которые решили стать попутчиками, и т. п.

Отличительной чертой таких площадок является то, что они позволяют продавцам выставлять товары или услуги для продажи и предоставлять клиентам простые инструменты для контакта. Очевидно, что цифровые (digital) технологии развиваются в направлении обеспечения более комфортного и быстрого взаимодействия клиента с компанией. Такая трансформация позволяет улучшать качество продуктов и услуг, автоматизировать производство и упрощать внутренние и внешние коммуникации [2, с. 68].

Интересным способом управления бизнесом в отличие от традиционных (иерархических) форм корпоративной организации является холакратия (отказ от жесткой корпоративной структуры, происходит от греческого слова «холос», обозначая нечто целое, являющееся частью более крупного). Термин «холакратия» происходит от греческого слова «холос», обозначая нечто целое, являющееся частью более крупного. Холакратия заменяет вертикальную иерархию горизонтальной, с более равномерным распределением ответственности и руководства в виде кругов, каждый из которых включает сотрудников, работающих над

\footnotetext{
${ }^{1}$ Переводят на русский по-разному - экономика совместного пользования, «долевая» экономика, даже экономика сотрудничества и участия. Включает в себя такие сервисы, как аренда вещей, совместное использование машин (каршеринг), жилья и т. п.
} 
одним проектом в самых разных ролях ${ }^{1}$. Основными принципами подобной структуры управления являются:

1) замена вертикальной иерархии горизонтальной;

2) отсутствие штатного расписания - штат сотрудников разделен на круги, каждый круг занимается разработкой определенного проекта, обязанности внутри круга разделены между всеми, каждый может быть задействован одновременно в разных кругах: при разработке одного проекта он - ведущий специалист, в другом - занимается рутинной работой;

3) личная ответственность работников и коллегиальное принятие решений, поскольку в данном случае, в отсутствие вертикальной иерархии, нет необходимости отчитываться перед вышестоящим начальством, однако работа должна быть выполнена, поскольку существует коллективная ответственность;

4) распределение обязанностей зависит от личных качеств или предпочтений сотрудников, график работы они согласовывают друг с другом, т. е. он максимально гибкий. Интересно то, что в некоторых компаниях сотруднику, освоившему какую-то определенную работу, выдается значок, подтверждающий его квалификацию, что дает ему право участвовать в большем количестве кругов (проектов);

5) открытость. Вся информация предельно прозрачна. Все данные раскрыты - от заработной платы до финансовой отчетности и результатов работы. Такой подход позволяет избавиться от недоверия в коллективе;

6) заработная плата: базовая с учетом вклада каждого в общую работу, причем в определении величины заработной платы принимает участие и сам работник.

Такая модель не имеет выраженных атрибутов власти, а отсутствие власти приводит к невозможности злоупотребления ею, а также к лоббированию интересов - продвижения «своих» людей по служебной лестнице, т. е. обеспечивает большую вовлеченность сотрудников в рабочий процесс и т. п. ${ }^{2}$

Компаний, применяющих холакратию, в настоящее время не так много. На cайте Holacracy.org упоминается о более 300 организаций, внедривших в том или ином виде описанную горизонтальную структуру. Среди них Airbnb; блогплатформа Medium; разработчик видеоигр Valve.

Практически всем знакома ситуация, когда политики начинают вести себя неадекватно под воздействием больших денег и больших полномочий, представляя при этом интересы большинства. Особенно это заметно на примере распределения региональных бюджетов, когда от имени большинства политики действуют не в их интересах. Подобные ситуации становятся причиной возникновения новых механизмов управления государственными и муниципальными финансами,

\footnotetext{
${ }^{1}$ Холакратия: зачем крупные компании отказываются от менеджеров и жесткой корпоративной структуры [Электронный ресурс]. URL: http://www.furfur.me/furfur/ freedom/freedom/216371-holokratiya

${ }^{2}$ Холакратия: зачем крупные компании отказываются от менеджеров и жесткой корпоративной структуры [Электронный ресурс]. URL: http://www.furfur.me/furfur/ freedom/freedom/216371-holokratiya
} 
таких как партиципаторное бюджетирование ${ }^{1}$, которое позволяет гражданам участвовать наравне с администрацией в принятии решений, в формировании и контроле бюджета.

Для участия в распределении бюджетных средств любого гражданина формируется специальная бюджетная комиссия или ассамблея (как правило, путем жеребьевки). На уровне ассамблеи жители определяют локальные приоритеты развития и голосуют за конкретный проект или инициативу, которая должна быть профинансирована, местные власти реализуют данный проект, а жители следят за его исполнением. Такой механизм позволяет ограничить централизованное управление, а также осуществить принцип равноправного доступа всех жителей к принятию решений существующих проблем².

Если рассматривать бизнес определенной компании с точки зрения осуществляемых бизнес-процессов и выполняемых функций, то можно оценить, какие функции будут в ближайшее время трансформироваться под влиянием цифровых технологий, поскольку уже накоплен некоторый опыт их внедрения в реальные бизнес-процессы. В табл. 1 отражена попытка привязать определенные технологии к функционалу бизнес-модели.

Таблица 1

Перспективы применения цифровых технологий для совершенствования бизнес-процессов компании (разработано автором)

\begin{tabular}{|c|c|c|c|}
\hline $\begin{array}{c}\text { Выполняемая } \\
\text { функция }\end{array}$ & $\begin{array}{c}\text { Применяемая } \\
\text { бизнес-модель [3] }\end{array}$ & $\begin{array}{l}\text { Подсистемы } \\
\text { функции }\end{array}$ & $\begin{array}{l}\text { Цифровые } \\
\text { технологии }\end{array}$ \\
\hline \multirow[t]{3}{*}{ ПРОИЗВОДСТВО } & \multirow{3}{*}{$\begin{array}{l}\text { - отказ от посред- } \\
\text { ников; } \\
\text { - дробление; } \\
\text { - франшиза; } \\
\text { - лизинг; } \\
\text { - кастомизация }\end{array}$} & дизайн & $\begin{array}{l}\text { - дополненная реальность; - } \\
\text { голографические интерфейсы }\end{array}$ \\
\hline & & $\begin{array}{l}\text { сырье и комплекту- } \\
\text { ющие продукты }\end{array}$ & $\begin{array}{l}\text { - 3D-печать; } \\
\text { - редактирование генома }\end{array}$ \\
\hline & & $\begin{array}{l}\text { процесс производ- } \\
\text { ства }\end{array}$ & $\begin{array}{l}\text { - франшиза одного лица; } \\
\text { - искусственный интеллект }\end{array}$ \\
\hline \multirow[t]{3}{*}{ УПРАВЛЕНИЕ } & \multirow{3}{*}{$\begin{array}{l}\text { - холакратия; } \\
\text { - партиципаторное } \\
\text { бюджетирование; } \\
\text { - краудсорсинг; } \\
\text { - партнерские про- } \\
\text { граммы; } \\
\text { - low-touch (низкий } \\
\text { уровень обслужи- } \\
\text { вания, например } \\
\text { ikea, лоукостеры и } \\
\text { пр.) }\end{array}$} & $\begin{array}{l}\text { организационная } \\
\text { структура организа- } \\
\text { ции }\end{array}$ & $\begin{array}{l}\text { - технологии совместного поль- } \\
\text { зования и управления (шеринг } \\
\text { экономика); } \\
\text { - введение горизонтальной } \\
\text { структуры }\end{array}$ \\
\hline & & финансирование & $\begin{array}{l}\text { краудфандинг или фандрайзинг } \\
\text { (англ. fundraising - «привлече- } \\
\text { ние средств») }\end{array}$ \\
\hline & & $\begin{array}{l}\text { способ распределе- } \\
\text { ния бюджета, учета } \\
\text { и расчетов }\end{array}$ & $\begin{array}{l}\text { - механизмы партиципаторного } \\
\text { бюджетирования; } \\
\text { - блокчейн }\end{array}$ \\
\hline ПРОДАЖИ & - маркетплейс; & реклама & - интернет; \\
\hline
\end{tabular}

\footnotetext{
${ }^{1}$ Партиципаторное бюджетирование - это распределение части муниципального бюджета города его жителями, при котором сами горожане решают на специальных собраниях, как тратить деньги - на строительство скейт-парка для детей или озеленение дворов. 2 Публичный двор: как отменить чиновников и финансировать свой район самостоятельно [Электронный ресурc]. URL: http://www.furfur.me/furfur/changes/ changes/215041partitsipatornoe-byudzhetirovanie
} 
E. И. Куликова. Модернизация бизнеса компании под влиянием цифровых технологий

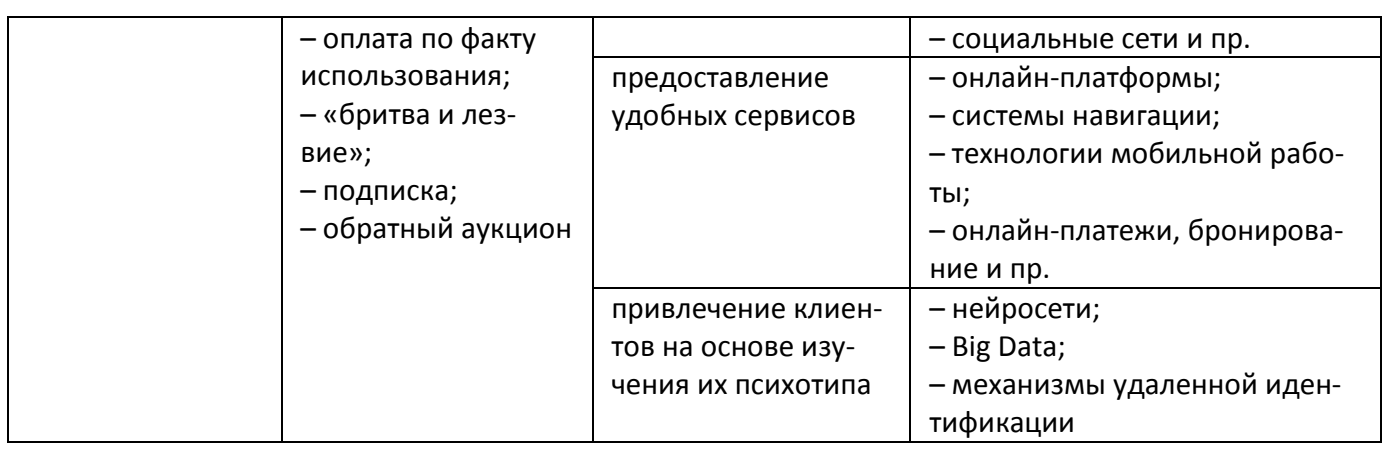

Анализ табл. 1 показывает, что цифровые технологии дают мощный импульс развитию всех бизнес-процессов в любых сферах деятельности и отраслях. Кроме того, новые технологии и продукты на их основе практически безграничны. Более того, в настоящее время предприниматели заняты проблемами монетизации тех или иных разработок. Все это свидетельствует об активизации предпринимательской деятельности в российской экономике под влиянием развития цифровых технологий, о чем свидетельствует большое количество стартапов на российском рынке ${ }^{1}$.

Однако нельзя не обратить внимания и на риски, возникающие при использовании цифровых технологий. Причем эти риски связаны не только с техническими аспектами. Например, транзакции, проведенные в системе распределенного реестра (блокчейн), нельзя отменить, а тем более отыграть назад, в первую очередь в связи с отсутствием правовой базы, регламентирующей диапазон их применения. Такие технологии, как редактирование генома (с неизвестными для экосистемы последствиями); сбор и использование информации о любом человеке в сетях и по поисковым запросам, оплатам и т. п. на основе технологии Big Data; создание торговых онлайн-площадок с широким перечнем продуктов разнообразного качества (известная интернет-платформа «Silk Road», где осуществлялась торговля оружием и наркотиками); отсутствие обратной связи с потребителем при оказании услуг, приводящее к невозможности оспорить качество услуги и получить компенсацию за некачественное обслуживание и тому подобное, требуют контроля со стороны государства и общества. Кроме того, разработки в области искусственного интеллекта и генной инженерии требуют огромных затрат, финансирование которых в состоянии обеспечить только государственный бюджет.

Таким образом, понятно, что цифровые технологии меняют мир, в котором мы живем, и это объективный процесс, который требует своего осмысления, анализа, в том числе рисков применения технологий и продуктов и создания систем защиты от рисков. Не все может сделать бизнес, роль государства в этом процессе велика, поэтому, вероятно, будут возникать новые технологии взаимодействия бизнеса и органов государственного управления на благо развития и процветания нашего общества.

\footnotetext{
${ }^{1}$ Крицкая М. 17 бизнес-моделей. Придумать новую или использовать старую? [Электронный ресурс]. URL: https://kontur.ru/articles/5030
} 


\section{Литература}

1. Булгатова Ю. С., Сандакова Л. Г., Цыренов Д. Д. Информационные технологии в управлении деятельностью бизнес-систем в условиях трансформации российского общества: монография. Улан-Удэ : Изд-во Бурят. гос. ун-та, 2016. 136 с.

2. Куликова Е. И. Цифровизация как основной тренд развития финансовых услуг // Финансовая жизнь. 2018. № 4. С. 67-70.

3. Лосева А. Ю., Цыренов Д. Д. Современные информационные системы: теория и практика : монография. М. : Русайнс, 2018. 102 с.

4. Прикладная бизнес-информатика: теория, методология, практика: монография / Д. Д. Цыренов [и др.]. Улан-Удэ : Изд-во Бурят. гос. ун-та, 2016. 148 с.

\section{BUSINESS MODERNIZATION UNDER THE INFLUENCE OF DIGITAL TECHNOLOGIES}

\section{Elena I. Kulikova}

Cand. Sci. (Econ.), A/Prof.,

Financial University under the Government of the Russian Federation

49 Leningradsky Prospect, Moscow 125993, Russia

E-mail: kulikovae@yandex.ru

The article concerns the highly topical issue of the introduction of digital technologies into economic practice, since the world economy today impose high requirements to their development, which initiated the digital economy era. Digital technologies are based on the needs of society in the complex of institutional reforms aimed at the modernization of distributive and redistributive relations. Special attention is paid to the study of business processes and business models transformation as a result of digital technologies development in various segments of business, such as management, control of production processes, sales, etc. We have identified the opportunities for the development of Russian companies and the uses of certain products in business processes, as well as outlined the risks of their usage.

Keywords: business processes; business models; digital technologies; online platforms; artificial intelligence; entrepreneurship; sharing economy. 